in hydrocarbon flames indicates that carbon formation can be prevented either by providing an alternative reaction which consumes hydrogen atoms or a state of affairs which renders them ineffective.

It seems probable that, in the hydrogen and hydrocarbon flames, the gaseous additives function either as third bodies in exothermic reactions leading to the destruction of hydrogen atoms, or as second bodies which effectively reduce the collision frequency of these atoms with each other or with hydrocarbon molecules. In discussing the nature of the former reactions, at least three possibilities may be considered :

(i) $\mathrm{H}+\mathrm{H}+X \rightarrow \mathrm{H}_{2}+X$ ( $X$ is the additive)

(ii) $\mathrm{H}+X \rightarrow \mathrm{H} \ldots X, \mathrm{H} \ldots X+\mathrm{H} \rightarrow \mathrm{H}_{2}+X$

(iii) $\mathrm{H}+\mathrm{O}_{2}+X \rightarrow \mathrm{HO}_{2}+X$.

As a third -order reaction involving two species present in small quantity, reaction (i) will occur infrequently. Reaction (ii) is an adzptation of (i), involving two consecutive second-order reactions (the second following closely on the first and a 'sticky' collision between $H$ and the additive being assumed). Equation (iii) is more likely to be important, on collision grounds, than (i) owing to the greater concentration of molecular oxygen than atomic hydrogen; but the evidence for the existence of $\mathrm{HO}_{2}$ in hot normal flames is meagre. The energy change in (iii) being unknown, one cannot decide whether sodium atom excitation (requiring 48.3 k.cal.) could occur due to (iii). Other reactions are possible (for example, involving $\mathrm{OH}$ ), but it is certain that at least one hydrogen atom is involved.

Even without knowing the exact nature of the key reaction, some conclusions can be drawn. Thus it is known that sodium atoms will emit the $D$ lines by excitation in a hydrogen discharge, and it has sometimes been suspected that their excitation in flames is chemiluminescent; the above experiments lend support to this view, though they do not eliminate a role of hydrogen atoms in the generation rather than in the excitation of sodium atoms. In any event, the matter is relevant to the $D$-line reversal method of flame temperature measurement, and the sensitivity of hydrogen flames (compared with others) to the presence of sodium is accounted for. Moreover, the relation between the concentration of sodium in flames and the extent to which it is excited will depend much on the chemistry of the flame processes.

The observations with hydrocarbon flames imply that important initiating reactions of carbon form. ation are of the form :

$$
\begin{gathered}
\mathrm{C}_{n} \mathrm{H}_{m}+\mathrm{H} \rightarrow \mathrm{C}_{n} \mathrm{H}_{m-1}+\mathrm{H}_{2}, \\
R-\mathrm{CH}=\mathrm{CH} R+\mathrm{H} \rightarrow R-\mathrm{CH}-\mathrm{CH}_{2} R ;
\end{gathered}
$$

the former reaction was invoked ${ }^{3}$ to account for the products of reaction from hydrocarbons (other than methane) and atomic hydrogen at room temperature. The stripping or addition of hydrogen atoms will be followed by polymerization of the freshly formed hydrocarbon radicals, the two processes together leading finally to solid carbon formation in flames.

In connexion with the cooling of hydrocarbon flemes by additions of foreign gas and with the general question of the effect of temperature on carbon formation, it may be recalled that $V$. B. Lewes ${ }^{3}$ was of the opinion that carbon formation in all hydrocarbon flames was preceded by the formation of acetylene, the strongly exothermic decomposition of which to carbon and hydrogen caused the former to radiate : added gases (carbon dioxide, nitrogen, etc.) lowered the temperature sufficiently for the formation of acetylene to be prevented. The following observation implies, however, that the cooling effect is not all-important in relation to carbon formation. The critical concentration of carbon dioxide required to extinguish the luminosity of a methane flame was found to be unchanged when the mixed gases fed to the burner were preheated : on Lewes's view, more carbon dioxide should have been required.

'This work, including relevant spectroscopic measurements, will shortly be reported in full. My thanks are due to several colleagues : Dr. D. T. A. Townend in discussing the significance of Smith's luminescence experiments, directed attention to the probable role of large molecules as targets for the removal of hydrogen atoms; Dr. D. H. Bangham gave invaluable advice throughout the course of the work; and Dr. M. S. Iyengar assisted with some of the experimental work.

' (a) Smith, E. C. W., Second Arthur Duckham Research Fellowship Report, Inst. Gas. Eng., 1940. (b) Townend, D. T. A., Jubilee Memorial Lecture of the society of Chemical Industry, Chem. and Indust., 23, 346 (1945). (c) Townend, D. T. A., lecture to the annual general meeting of the Gas Research Board. 1949 ; atoms in combustion processes", by J. R. Arthur and D. T. A. Townend (in the press).

'Bonhoeffer, K., and Harteck, P., Z. phys. Chem., 139, 64 (1928). " Lewes, V. B., Trans. Chem. Soc., 69, 322 (1892); Proc. Roy. Soc.,
55, 90 (1894); 57, 344 (1895).

\section{PLASTIC FLOW OF UNMATURED LINOLEUM}

N January 23, the Linoleum Research Council held a symposium at the Grosvenor Hotel, London, the subject being "The Plastic Flow of Unmatured Linoleum". About forty people were present, of whom more than half were men of science and technologists from the linoleum industry. In opening the meeting, Mr. T. McQuillen, chairman of the executive,committee, pointed out that the policy of the Linoleum Research Council is to endow research in suitable institutions and to supplement this effort by encouraging co-operative research within the industry; the symposium was the outcome of the second line of approach. Dr. S. R. W. Martin, the superintendent of research, then explained the programme for the day, and pointed out that six papers would be presented, which had been circulated at least a week beforehand. Each contributor was allowed 15-20 minutes to outline the salient points of his paper, and at the end of the proceedings time was given for a general discussion.

Mr. A. G. Ward (director of the British Gelatine and Glue Research Association) outlined work on the rheology of unseasoned linoleum which he has carried out at the Building Research Station, Watford, for Messrs. Michael Nairn and Co., Ltd., the primary object being to evolve a technique which could be used for research purposes and routine control, and the results of which could be correlated with actual behaviour of material in a calender. He emphasized that, although in industry formulæ are made up on a weight basis for convenience, it is the volume ratio of the constituents which is of importance in work of this nature, and in the first part of his paper he described methods for determining the true density of some of the components of a linoleum mix ground cork, specific gravity 1·25. After preliminary 
experiments of an exploratory nature on the flow of linoleum compositions, an extrusion technique was evolved. Calendering, of course, can in many respects be considered as two-dimensional extrusion. It is possible with such an apparatus to work with pressures which are of approximately the same order of magnitude as those in use on an actual calender. The extrusion apparatus described can be used with a series of nine extrusion nozzles (three different lengths, each of three different diameters) in order to measure end effects, or with one nozzle for routine testing. Mr. Ward discussed the significance of the results he has obtrined in relation to the manufacture of linoleum, particularly with respect to the effects of combined hydrostatic pressure and shearing stress as in the calendering process.

An extrusion apparatus, which has been developed from the prototype outlined by Mr. Ward, was described by Messrs. F. T. Walker and J. Arnot (Michael Nairn and Co., Ltd.). By extruding unseasoned linoleum in this apparatus, the behaviour under calendering conditions and the effect exerted by the various conventional fillers can be demonstrated. The relationship between temperature and extrusion-rate at constant pressure, for linoleum mixes containing known volumes of fillers, was shown in a series of curves. A constant factor appears to exist between the equivalent amounts of any two fillers which have the same effect on flow. Apart from sheet formation, marble and other decorative effects are dependent on the flow characteristics of the unseasoned mix. A few curves of related floorcoverings, for example, asphalt tile and polyvinylchloride flooring, were given. The problem of solidliquid mixtures was examined by Mr. P. Rigden (Road Research Laboratory, Harmondsworth). He quoted information derived from filler-binder systems as used in the road-building industry and showed how the analysis of rheological data gives information of the structure and make-up of the particular system. In a practical paper describing the use of a penetrometer-type instrument to measure the deformation of unmatured linoleum, Mr. C. W. Falkner (Linoleum Manufacturing Co.) gave some interesting facts correlating results obtained on this instrument with composition of the sample under test. An attempt has been made to study quantitatively the flow properties of the linoleum plastic mix, with special reference to changes in workability and plasticity with temperature.

A method of evaluation of the rheological properties of linoleum composition was described by Messrs. G. D. Rack and F. J. Rigby (Jas. Williamson and Son, Ltd.), which is based on a creep-curve method, one that needs only the simplest of apparatus. In practice, samples of linoleum composition after calendering are cut into strips of standard length and the rate of extension measured with different applied stresses. Experimental work shows the effect of mixing-time on linoleum compositions containing all cork (or wood flour) as the cellular filler, the effect of the type of filler and the effect of the age of the sheet. Although there are certain limiting factors to the use of this technique, the method needs no expensive apparatus and is within the reach of all investigators. Mr. R. W. Whorlow (Research Association of British Rubber Manufacturers) described the relative merits of various types of instruments used for the measurement of plasticity in the rubber industry and, in particular, discussed the merits of the rotational instruments used, which in some cases had been deprecated during the discussion at the symposium. The methods of using these various instruments and possible ways of modifying them to be of use to the linoleum industry were dealt with.

In summing up, Mr. Ward said that certain points stand out very clearly; one of them, the measurement of composition on a volume basis, is a fruitful approach. He suggested that by making a start with the binder in the composition and by studying its properties in detail, in a similar way to the work which has been carried out at the Road Research Laboratory, some important and interesting data could be obtained. Mr. Ward was of the opinion that, although the extrusion type of apparatus is particularly useful, there may be a limit to its usefulness, and it is not easy to separate certain effects. The theory of calendering was discussed at the symposium, and this is tied in many ways to extrusion; but he suggested that the industry should also consider other fields, that is, in the early stages of manufacture, as calendering is not the only process used in making linoleum.

\section{QUANTITATIVE ECOLOGY OF PLANKTON}

$T$

HE population of plankton organisms in the sea is composed of plants and animals of very assorted sizes and shapes. Of these, the microscopic plants are producers, and the smaller animals are consumers-but also producers of fish-life. The productivity of the sea is dependent upon a complex of physical and chemical conditions, chief among which are the radiation of the sun and nutrient substances containing phosphorus and nitrogen.

Our knowledge of this many-sided picture is now sufficiently detailed to allow attempts at mathematical treatment. The accumulation of the necessary data has taken many years of painstaking and sustained research in many directions, much of which has needed the elaboration of special methods. By this means quantitative knowledge has been obtained on the seasonal and regional changes in amounts of nutrient salts, the penetration of the sun's radiation into the sea, and the conditions leading to stability or unstability of the water column and hence the turbulence.

The collection of the information on the living populations, although it was started earlier, has been slower and less organised, largely owing to the varied interests of the research workers. First, the constituent members of the flora and fauna had to be described and identified; studies of their comparative abundance and seasonal and regional distribution were ends in themselves, as were their life-histories. But when sufficient was known, attempts were soon made to correlate the seasonal and other changes in the populations with the physical and chemical conditions. In general, these correlations have been expressed in numbers of different individuals of the population. Perhaps this was rather natural, since estimations were chiefly made by botanists and zoologists who had interests in the organisms as such. But a correct assessment of the overall production can only be made by chemical means. Information on photosynthesis, respiration, and metabolism of plankton plants and animals has been obtained by experiment. Assessment of quantity of plant life in 